\title{
LXI. On electricity and steam
}

\section{Reuben Phillips Esq.}

To cite this article: Reuben Phillips Esq. (1849) LXI. On electricity and steam , Philosophical Magazine Series 3, 35:239, 490-497, DOI: 10.1080/14786444908646402

To link to this article: http://dx.doi.org/10.1080/14786444908646402

$$
\text { 册 Published online: } 30 \text { Apr } 2009 .
$$

Submit your article to this journal

LII Article views: 4

Q View related articles $\asymp$ 
conical one, has its $x$ and $y$ dependent on the periodic $\cos \mu$; which quantity enters explicitly and implicitly in the differential expression for the centripetal force to the focus, which is therefore uot identical with the Newtonian law.

November 26, 1849.

S. M. Drach.

LXI. On Electricity and Steam. By Reuben Phillips, Esq* *

35. THIS paper is a continuation of a former one (Phil. Mag., vol. xxxiv. p. 502), wherein are described some magnetic actions produced by steam in the act of condensation. I regarded those motions as the effect of dynamic electricity, and then endeavoured to obtain the static effect, which I think I have done.

36. An electrometer was constructed in the following manner :-A straight slip of thin metal, about 4 inch wide, was bent at some distance from one end, the direction of the motion in bending being in a plane perpendicular to the original surface of the plate and parallel to its length, and the bending was continued until the included angle was 0 ; the bend was opened a little, the $\epsilon$ nd of a slip of gold-leaf inserted, and the whole rendered secure with a binding-screw. Previously, however, the plate at that part which was close to the end that had been doubled in, had been bent in the same direction as before, four times at right angles, so as to leave a little projection across the plate, over which the gold-leaf hung; the object being to keep the gold-leaf so far from the metal plate, that a rapid inspection sufficed to show that the former was free to move. The gold was the length of one side of the usual gold-leaf, and the metal plate extended parallel with it to its lower end. 'The doubled portion was now fitted into a slit in a cork, which was then inserted into a glass tube, the end of the bent portion projecting about $\frac{3}{4}$ inch beyond the external end of the cork. The other end of the glass tube also held a cork, through which a straight metal plate passed extending parallel to the gold-leaf. The tube was about $\cdot 9$ inch diameter and $5 \frac{1}{2}$ inches long, and the ends were covered with sealing-wax; however, care was always taken to connect the plate of the lower cork with the earth. The whole could be supported on a small wooden stand.

37. A singular appearance, but not connected with electricity, is presented by this electrometer when either of the metal plates is made to vibrate, as by a slight tap; for the

* Communicated by the Author. 
gold-leaf is then powerfully attracted by, and drawn into contact with the vibrating plate. I suppose this observation is new, and very significant with regard to theories of attraction and repulsion, although $I$ have not pursued it further.

38. As this electrometer was very sensitive, I more generally employed another, with two short gold leaves, and which was very far from being a sensitive instrument. This instrument was always employed except where I have mentioned that the single-leaf electrometer was used.

39. 'Throughout these experiments the steam was at $40 \mathrm{lbs}$. on the inch, and was supplied from the same little boiler and discharged horizontally as before (7.).

40. The Armstrong's condenser was removed, and the brass jet (9.) was united to the cock of the boiler by two short brass connecting pieces. This brass jet originally belonged to an oxyhydrogen blowpipe, and its shape was slender and conical, and the small hole at the end of the jet from which the steam escaped was $\frac{1}{4}$ inch long, the remaining portion of the bore was $\frac{1}{8}$ inch diameter. The boiler communicated with the electrometer by means of a wire. When the cock was opened, the boiler became negative.

41. In order to collect the electricity of the steam, I used a piece of wire-gauze, insulated and supported on a stand, and which by means of a wire could be nade to impart its electricity to the electrometer; the extent of one side of the piece of wire-gauze was about 2.5 square inches. The electricity of the steam was thus found to be positive.

42. A straight glass tube about 3 feet long and $\cdot 4$ inch diameter, was placed horizontally with the brass jet projecting into it to the extent of the $\frac{1}{5}$ th of an inch; the tube was also supported so that an annular space existed between the end of the jet and the tube. In order to ascertain the electrical state of the inside of this, or any other tube, a few inches of its length were covered externally with a piece of tin-foil and bound on with wire, the other end of which could be taken to the electrometer.

43. When the steam was turned on, the tube and boiler both became negative. A connexion existed between the tube and the boiler; for when the leaves of the electrometer were divergent, touching the boiler made them collapse. Sometimes the first action of the steam was to make the leaves diverge to a small extent, then to make them approximate a little, and then to cause them to open much more with a negative charge; but when the connexion between the tube and the electrometer was broken before the approximation took place, the instrument was found to be positively charged. 
The wire-gauze being placed in the steam as it issued from the end of the glass tube showed that it was positive.

44. A glass tube, 3 feet 10 inches long and $1 \cdot 1$ inch diameter, was substituted for the former tube. With this tube all the foregoing effects were observed, but they were more powerful.

45. These experiments are only exhibitions of frictional electricity ; and the different states of the tube are principally produced by the tube taking its charge, either from the brass jet or from the excited steam that issued from it.

46. The Armstrong's condenser was now interposed, with water in it, between the boiler and the brass jet; and the smaller tube (42.) had the end which came to the brass jet fitted with a good cork, through which the brass jet passed and projected into the tube much as before; the joint was then made tight with caoutchouc and thread. To ascertain the state of the steam, I employed a piece of wire gauze, $6 \frac{1}{2}$ inches by 4 inches, attached by means of stout wire to an insulating handle, by which the gauze could be held in the steam and then taken to an electrometer. This wire-gauze collector was generally used in the following experiments.

47. The steam being turned on, the tube and boiler became positive. When the wire-gauze was held at about an inch or two from the end of the tube, it took from the steam a negative charge; and at the distance of something more than a foot, the gauze also acquired a negative charge which affected the single-leaf electrometer; and at intermediate positions the charge was still negative.

48. When the condenser was removed, and the jet was screwed into the cock of the boiler, everything else being as before (46.), no decided electrical effects were observed; but when the glass tube was also removed, then, having connected the boiler with the single-leaf electrometer and cautiously turning the cock, it was discovered that at a particular pressure the boiler became positive, and at much higher or lower pressures negative.

49. Now I regard these electrical effects as frictional, and possibly similar to those alternations in the electrical state of the boiler observed by Mr. Armstrong. (Phil. Mag. vol. xxiii. p. 202.)

50. While the steam was escaping into the air from the brass jet as above, I made some attempts to ascertain whether the steam was positive or negative; the electricity was very feeble, on which account 1 did not care much about it, but the little that I obtained was decidedly positive. This may have arisen, although it is improbable, from the boiler becoming 
negative, but it is more likely that the steam was rendered feebly positive from a cause which I now proceed to mention.

51. The condenser and jet were arranged as in the experiment (46.), and the smaller glass tube instead of being fastened on with cork and India rubber stood before the jet as formerly (42.). The steam being now turned on, the boiler and tube became positive. When the wire-gauze was about 1 inch from that end of the glass tube from which the steam was escaping, it took a negative charge; but at the distance of about a foot, the larger wire-gauze collector being employed, the steam communicated a powerful positive charge to the single-leaf electrometer. The electricity of the boiler and tube, and the positive electricity of the steam, were much stronger than the positive and negative electricities of the preceding experiment with a tight joint between the tube and jet. The negative charge was most probably given to the gauze by the friction occasioned by the violent rush of steam and air against it.

52. The larger glass tube (44.) was put in the place of the foregoing and carefully adjusted like the former tube, so that the central line of the path of the steam should lie as nearly as possible in the axis of the tube. The boiler and tube were positive. A connexion existed between the tube and boiler, for when the steam was passing and the leaves of the electrometer were greatly divergent, touching the boiler made them collapse to a comparatively small amount. When the gauze collector was held at about an inch from the end of the tube, a positive charge was obtained, and at a distance of 9 inches a powerful positive charge was still obtained; further experiments in this direction were prevented by a wall.

53. By means of India rubber, the end of the glass tube at the brass jet was closed, which caused the electrical effects to diminish to such an extent that the single-leaf electrometer indicated but doubtful traces from either the tube or steam.

54. A short glass tube, 14 inches long and of the same bore as the preceding, was substituted for it. The tube was always positive, and the boiler, except in one instance, neutral or positive. The larger collector being held, from that end of the tube from which the steam was escaping, at distances varying from 1 inch to 2 feet 6 inches, gave always a powerful positive charge.

55. The glass tube was now removed and the larger collector held in the steam at about 9 inches from the end of the brass jet; the boiler, collector and electrometer being electrically united. An abundance of positive electricity was obtained, which would doubtless have been obtained at a much greater distance. 
56. The piece of a gun-barrel (20.) was now placed with proper precautions before the jet, and by means of wire connected with the boiler. The boiler was positive, and the steam powerfully positive even at a distance from the jet of 4 teet 3 inches, the current of air at that distance being a mere breeze; and I doubt not that had it not been for the wall, I could easily have obtained plus electricity at double the distance. From this it clearly follows that the plus electricity of the steam cannot be generated by friction ayainst the gauze. Neither does friction in the tube generate it, for the effect was obtained without a tube (55.); nor can it be generated by friction in the brass jet, for this frictional electricity was found to leave the boiler negative, which negative electricity was not nearly equivalent to the positive of the steam (55.); to which I may add the similar experiments with the tubes, the tubes being evidently collectors only and not generators of the electricity of the steam.

57. It would seem as though positive electricity only, without negative, was generated in these experiments; however, it is not so.

58. The single-leaf electrometer was now placed in the vialholder of a microscope, through which the motions of the goldleaf were observed by a power of about 200 diameters, a nicrometer eye-piece being employed. Also a thin piece of metal, 2 inches by 6 inches, was fixed on an insulated support, the greater length of the plate being about perpendicular to the horizon. This metal plate was now placed at a little distance from the end of the former gun-barrel arrangement (56.), and sufficiently distant from the path of the steam to be out of the way of the straggling drops of water ; this screen was now connected with the electrometer, and the boiler carefully connected with the earth. When the steam was turned on, the electrometer received a negative charge. The extent of the motion of the leaf was very variable, depending, I think, on the amount of water discharged with the steam; on the average, 1 reckoned it about five micrometrical divisions. A brass tube, 6 inches long and $\frac{1}{2} \frac{7}{0}$ inch diameter, was now jammed on the end of the gun-barrel, to increase its length, and the inducteous plate was placed at the end of it, as before at the end of the gun-barrel. The steam now being turned on, the leaf moved over between twenty and thirty divisions.

59. It was easy to become convinced that these motions of the leaf were really produced by induction, by turning on the steam and allowing the leaf to obtain its deviation and then quickly shutting off the steam, when the leat would promptly fall back. Also with the brass tube on, I managed to charge the instrument positively by turning on the steam, then open- 
ing a communication for a moment between the earth and the plate, and then shutting off the steam.

60. When the brass tube was on the end of the gun-barrel, the leaf seldom returned to its starting-point when the current of steam was stopped, and the instrument appeared to have acquired a permanent charge, which was negative, and appeared to go on increasing with the time that the stean was allowed to escape. It was found, too, that as the inducteous plate was removed in a direction perpendicular to the path of the steam, the first-mentioned effect or induction rapidly diminished, but that the power which appeared to give the permanent charge scarcely underwent any alteration, even when the distance from the path of the steam was increased to 9 inches, the greatest distance the apparatus would allow. I have but little doubt that this apparently permanent charge was principally produced by the inductric action of the steam-cloud.

61. From the foregoing it is seen that the jet of steam im. parts positive electricity to any substance that it touches, while at the same time the steam, as a whole, may be more or less negative. These facts will very well comport with the idea that the particles of water are positive and the gaseous matter negative; hence when the current passes through a tube or touches a piece of wire-gauze, the particles of water become more or less separated from the air and vapour, leaving them negative. That the negative electricity of the gaseous matter is not immediately transferred to the particles of water, is, I suppose, due to the non-conducting power of gases.

62. When these electric effects are being produced by the jet of steam, a peculiar rough sound is heard, which is dependent on the discharge of water with the steam; for when the jet was screwed into the cock of the boiler, I never heard any other sound than a smooth sibilation; and when water was discharged with the steam, if its quantity was not quite sufficient, the smooth hiss only was obrained. At such times, the steam, as it issued from the jet, on being examined, was found to be, for the distance of $\frac{1}{8}$ th of an inch from the end of the jet, transparent, with the exception of a thread-like appearance of cloud extending through the clear steam parallel to its path. Presently, from a lowering of the pressure, or other cause, this little cloud expanded all round the jet, and then looked like a frustum of a little right cone of cloud stuck on the end of the brass jet, the roar being at the same time perfectly developed. These effects were obtained without any tube belore the jet.

63. With the arrangement described (51.) very instructive results were occasionally obtained; the tube was connected 
with the electrometer. Sometimes, when the steam was turned on, the roar was absent, and then the electrometer was with difficulty acted on; then suddenly the roar was set up, and the electrometer was promptly and powerfully affected.

64. It appears to me that when water is discharged with the steam and a smooth sibilant sound only obtained, that the water passes off as a little stream from one part of the orifice, but that with the roar the water escapes about equally from each part of the hole. In the latter case it is doubtless much more finely comminuted.

65. When a jet of steam and water thus escapes into the air, the particles of water, from their size and consequent weight, will soon move faster than the atoms of water which were discharged in the gaseous state. From this follows the question, Are the particles of water charged by rubbing against the gaseous matter? To this it must be answered, that this electricity was not generated in the former experiments (46, 53.), where water, gaseous matter and friction were present. Also, no experiment is known in which gaseous matter is certainly charged electrically by friction. (See Dr. Faraday's paper on Steam Electricity, Experimental Researches in Electricity, vol. ii. p. 106.)

66. A jet of steam being discharged into the air becomes magnetic (11.), which I attribute to currents of electricity passing from the hotter to the colder particles (33.), in this case steam and air ; the steam, or water which was discharged as steam, being positive, and the air negative. When particles of water are projected through the steam-cloud, I suppose they collect together the minute positive particles, thus becoming themselves positively electrified, leaving the gaseous matter negative. I have yet made no direct experiments to ascertain the minimum pressure at which these effects are produced, but I am certain they may be obtained at a much lower pressure than $40 \mathrm{lbs}$. on the inch.

67 . Since these electrical effects are produced by the transmission of drops of water through a steam-cloud in the act of formation, it appears to me that these electrical developments may occur in the atmosphere. In my experiments, the drops of water were so fine that they were separated with difficulty from the air, but I see no reason for supposing that the electrical action would be essentially different if the drops were so much larger as to separate themselves by their weight. Lightning will thus result from a rapid condensation, the descending rain and mist being positive, leaving the upper regions negative.

68. I would have this explanation of the cause of lightning 
to depend, at present, as little as possible on the mechanical violence of the drops of water; because some experiments, not yet fit for publication, seem to show that when steam and air at the same temperature are discharged into the atmosphere, the amount of water simultaneously discharged may be greatly reduced, perhaps to nothing.

69. The negative state of the air, which one would expect to find particularly strong just after a thunder-storm, may slowly discharge itself on the earth by conduction, or on the clouds, or rain, and thus to the earth by convection; nevertheless the direct tendency of lightning, according to this theory, is to rencler the upper regions negative; and the facilities for the return of this negative charge to the earth will decrease in some proportion as the altitude increases. The continual thunder-storms of the hotter climates may therefore gradually accumulate a powerful negative charge in the heavens. Suppose now, when the air is thus highly charged, that n column of mist sufficiently high and dense to act the part of an electric conductor to the positive earth and negative heavens should be interposed between them, the electricity would then pass as a series of disruptive discharges, and would, I suppose, be the aurora.

7 Prospect Place, Ball's Pond Road, 3rd December 1849.

LXII. Geometry and Geometers. Collected by T. S. DAvies, Esq., F.R.S. and F.S.A.*

No. IV.

THE printing of the three letters of John Bernoulli to Cramer, which I had designed to give as the next of this series of "gossipings," must be deferred for awhile; as, from particular considerations, I am led to think it desirable to confine myself, for the present at least, to matters of more purely English interest.

In $1747 \mathrm{Mr}$. Thomas Simpson published the first edition of his Elements of Geometry; and in $1756 \mathrm{Dr}$. Simson the first edition of his Euclid. In this latter work are two notes upon objections which had been raised in the former, to some of Enclid's processes. In $1760 \mathrm{Mr}$. Simpson published the second edition of his Elements, in which he defends himself with great earnestness on those topics; and Dr. Hutton (in his Life of Simpson, prefixed to the Select Exercises, ed. of

* Communicated by the Author.

Phil. Mag. S. 3. No. 239. Suppl. Vol. 35. 